\title{
Breves considerações sobre a documentação pedagógica
}

\author{
Brief considerations on pedagogical documentation \\ Breves consideraciones sobre documentación pedagógica
}

Recebido: 01/07/2021 | Revisado: 09/07/2021 | Aceito: 12/07/2021 | Publicado: 23/07/2021

\author{
Ruhena Kelber Abrao Ferreira \\ ORCID: https://orcid.org/0000-0002-5280-6263 \\ Universidade Federal do Tocantins, Brasil \\ E-mail: kelberabrao@gmail.com \\ Evelyn da Silva Santos \\ ORCID: https://orcid.org/0000-0001-8134-0928 \\ Universidade Federal do Tocantins, Brasil \\ E-mail: kelberabrao@gmail.com
}

\begin{abstract}
Resumo
Este trabalho tem por objetivo discutir o conceito de experiência trazido por Larrosa (2002), no texto Notas sobre a experiência e o saber da experiência, no processo formativo do professor, na perspectiva da documentação pedagógica, juntamente com outros autores. A partir disso, apresentamos narrativas que tratam de conceitos como: Educação Infantil, documentação pedagógica, formação docente, experiência e suas interfaces tendo por base diversos estudos bibliográficos. Por fim, destacamos o papel da documentação pedagógica, como uma experiência de aprendizagem do professor, possibilitando a sua constante formação docente.
\end{abstract}

Palavras-chave: Formação docente; Documentação pedagógica; Educação infantil.

\begin{abstract}
This work aims to discuss the concept of experience brought by Larrosa (2002), in the text Notes on experience and knowledge of experience, in the teacher's formative process, from the perspective of pedagogical documentation along with other authors. From this, we present narratives that deal with concepts such as: Early Childhood Education, pedagogical documentation, teacher training, experience and its interfaces based on several bibliographic studies. Finally, we highlight the role of pedagogical documentation, as a learning experience for teachers, enabling their constant teacher training.
\end{abstract}

Keywords: Teacher training; Pedagogical documentation; Child education.

\section{Resumen}

Este trabajo tiene como objetivo discutir el concepto de experiencia aportado por Larrosa (2002), en el texto Notas sobre la experiencia y el conocimiento de la experiencia, en el proceso formativo del docente, desde la perspectiva de la documentación pedagógica junto con otros autores. A partir de esto, presentamos narrativas que abordan conceptos como: Educación Infantil, documentación pedagógica, formación docente, experiencia y sus interfaces a partir de varios estudios bibliográficos. Finalmente, destacamos el papel de la documentación pedagógica, como una experiencia de aprendizaje para los docentes, posibilitando su constante formación docente.

Palabras clave: Formación de profesores; Documentación pedagógica; Educación infantil.

\section{Introdução}

A Educação Infantil, primeira etapa da Educação Básica, atende crianças dos 4 meses aos 5 anos e 11 meses, preconiza a organização do cotidiano alicerçada em três pilares: cuidar, brincar e educar (Brasil, 1996). É um espaço de educação formal, com especificidades próprias, por se tratar de bebês e crianças pequenas; o que a caracteriza com uma identidade única. Assim, já não é mais possível a oferta de um atendimento meramente assistencialista, voltado apenas para os cuidados dos pequenos. Por outro lado, a busca por um modelo de instituição escolarizante que prepara para a etapa seguinte, o Ensino Fundamental (EF), não é o seu objetivo, já que vai de encontro ao postulado de tratar as crianças em suas singularidades (Abrão, 2012, 2013).

A Educação Infantil é espaço privilegiado de convivência, construção de identidades coletivas, ampliação de saberes e conhecimentos de diferentes naturezas, por meio das práticas que atuam como recurso de promoção de equidade, 
oportunidades educacionais entre as crianças de diferentes classes sociais, do que, se refere ao acesso à bens culturais e possibilidades de vivências (Brasil, 2010).

Em seus achados científicos, Gandini e Edwards (2002) concebem a documentação pedagógica, enquanto, prática cíclica. Primeiramente, existe a fase da formulação de perguntas e inquietações, em seguida, passa-se à observação do objeto a ser desvelado, depois o registro e produção de informações relevantes; após a organização dos dados coletados e registrados; chegando a análise e produção dos registros elaborados; o que desencadeará novos questionamentos e a elaboração de novos projetos e planejamentos.

Logo, para os autores supracitados, ela consiste em um processo de investigação, reflexão, significação e ação que se retroalimenta, como em uma constante espiral ascendente resultado das aprendizagens das crianças e dos adultos envolvidos na prática pedagógica e de (re) criação de significados daquilo que emerge no cotidiano, do que se pensa e faz na Educação Infantil.

\section{Figura 1.}

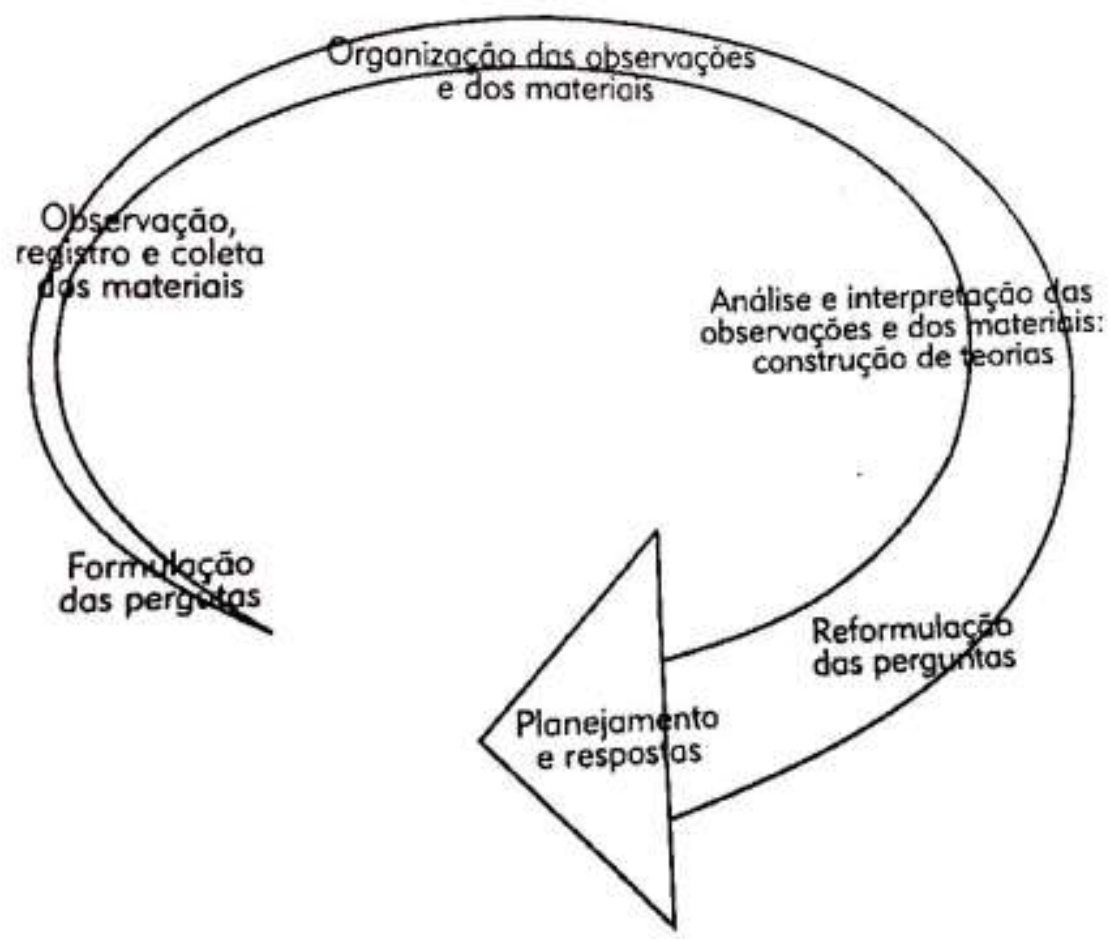

Fonte: Gandini e Edwards (2002, p. 162).

Nesse sentido, o professor não é o único que tem a possibilidade de documentar. Toda a equipe pedagógica envolvida na trama educacional da infância e que sejam movidas por uma inquietação, uma dúvida, um desejo pode realizá-la. Há a possibilidade de se documentar as crianças, para as crianças e com as crianças; para as famílias; para a equipe de professores e de funcionários e comunidade, em geral (Bresci et al, 2007).

Uma das dimensões da documentação é a sua comunicação e interação com as famílias e a comunidade escolar, o que possibilita a socialização das experiências infantis e ampliação da sua participação nos processos pedagógicos "a documentação pedagógica é o processo para registrar a aprendizagem - a aprendizagem das crianças, mas também a aprendizagem dos profissionais e a dos pais" (Oliveira-Formosinho; Formosinho, 2011, p. 35). 
As formas de se documentar variam de acordo, com o objeto, o destinatário e o objetivo a ser documentado. Fotografias do cotidiano, pequenos vídeos de brincadeiras e interações entre as crianças, produções de autoria dos pequenos, relatos de situações observadas, observações com uma pauta pré-definida, entre outros, são materiais potentes para uma futura documentação. Contudo, há de se ter rigor, pois a documentação pedagógica não é um compilado de registros. Para cumprir sua função ela precisa exercer o estatuto da reflexão na ação e da transformação da prática (Fochi, 2015).

É verdade que muitos de nossos professores já realizam algum tipo de registro, mas a simples realização do mesmo não se converte em uma verdadeira documentação pedagógica, uma vez que, a mesma além de dar visibilidade aos fazeres infantis "possibilita realizar, analisar e problematizar, de forma pública ou coletiva, aquilo que foi observado e registrado, assim como a inseparabilidade entre o documentado e o processo de planejamento, a definição do currículo, a escolha das atividades, a participação das crianças e das famílias no processo de documentação" (Barbosa e Fernandes, 2018).

Documentar envolve seleção, organização e elaboração de materiais e registros. Registros, os quais o professor combinará descrição e análise, tendo como premissa o processo reflexivo (Zabalza, 1994). Esses materiais podem ser valiosos na sistematização e construção da memória do próprio trabalho do professor, que reflete sua prática, avalia o processo das aprendizagens das crianças, retroalimentando planejamentos significativos, fomentando, assim, seu processo de formação e desenvolvimento profissional (Fochi, 2021).

Nessa proposta de pesquisa concebemos a documentação pedagógica, como uma ferramenta poderosa e produtiva de formação profissional docente, tendo em vista o potencial que imprimi, ao convidar o professor a pensar de outro modo sobre o que se sabe e o que se faz no cotidiano da Educação Infantil. Nessa perspectiva, reiteramos sua dimensão formativa, já que, estabelece uma forma de se relacionar inovadora, não só com as crianças, mas com os demais adultos com os quais o professor lida. Ao constituir-se como uma produção pedagógica, também se revela importante instrumento de trabalho, ao estimular o crescimento profissional, a qualificação do serviço a construção de condições de trabalho adequadas.

$\mathrm{O}$ rompimento com as pedagogias tradicionais que alocam as crianças em um lugar frágil, infértil e nulo torna-se imperioso (Fochi, 2015). A partir deste fato, justifica-se a importância da constituição de saberes e fazeres pedagógicos que deem conta da complexidade da vida e do cotidiano das relações das crianças pequenas na Educação Infantil (Abrão, 2012). Emerge a necessidade da constituição de professores com uma escuta atenta e um olhar sensível às infâncias vividas. Urge refletir a respeito da prática profissional, em uma tríade planejamento-ação-reflexão, na própria ação educativa (Fochi, 2021).

Este trabalho justifica-se pela possibilidade de apresentar a documentação pedagógica como uma prática que pode ser objeto de pesquisas mais consistentes na área da formação docente voltada, principalmente, para a complexidade da Educação Infantil. A relevância de tal prática vem sendo apontada em documentos oficiais como as Diretrizes Curriculares Nacionais para a Educação Infantil - DCNEIs (Brasil, 2009) que aponta a necessidade de "criar procedimentos para acompanhamento do trabalho pedagógico", considerando "a observação crítica e criativa das atividades, das brincadeiras e interações das crianças no cotidiano", por meio de "documentação específica" e a atual Base Nacional Comum Curricular - BNCC (Brasil, 2017) que corrobora que "parte do trabalho do educador é refletir, selecionar, organizar, planejar, mediar e monitorar o conjunto das práticas e interações (...) realizando a observação da trajetória de cada criança e de todo o grupo - suas conquistas, avanços, possibilidades e aprendizagens. Por meio de diversos registros, feitos em diferentes momentos tanto pelos professores quanto pelas crianças (como relatórios, portfólios, fotografias, desenhos e textos)".

Outro aspecto importante do estudo é o fato da pesquisadora trabalhar diretamente como técnica de referência e formadora de professores da Educação Infantil da Secretaria Municipal da Educação - SEMED, de Palmas/TO e perceber na organização das formações como muitas vezes elas são pontuais, pouco reflexivas, assistemáticas, não se constituindo num processo formativo, que leve os professores a identificarem suas potencialidades e fragilidades, mas, sim o cumprimento de 
uma agenda organizacional. Além disso, acreditamos que a documentação pedagógica é um artifício que fomenta a auto formação, sem necessitar das programações aperiódicas das secretarias de educação, o que confere ao professor autonomia diante das suas inquietações. Os professores da rede pública municipal contam, atualmente, com 16h de trabalho fora da sala de aula, para planejamento e estudos.

Outra questão que nos chama a atenção está diretamente relacionada aos registros na Educação Infantil. O registro realizado pelo professor pode ser um dos instrumentos da documentação pedagógica, uma vez que, registrar a prática significa estudar a aula, refletir sobre o trabalho e abrir-se ao processo de formação (Freire, 1996). Nos CMEIs de Palmas, os professores já realizam alguns registros acerca do que ocorre no cotidiano escolar. Contudo, são anotações mecânicas para atender a demandas burocráticas.

Por fim, um último aspecto que nos inquieta e provoca é que a maior parte das pesquisas, a respeito, da documentação refletem processos já estabelecidos ou em vias de implementação nas instituições de Educação Infantil. Nossa sede dar-se em analisar, apreender, perceber a experiência de iniciar esse processo e o que isso pode gerar em seus participantes.

\section{Problematização}

A Educação Infantil nas últimas décadas vem alcançando grandes conquistas. Passou a fazer parte da Educação Básica, a quantidade de pesquisas sobre a área cresceu, os professores possuem em sua maioria a formação mínima exigida curso médio normal/magistério (Gatti; Barreto, 2009).

Contudo, a especificidade da sua identidade, a torna mais complexa quando se trata da formação profissional docente. As grades curriculares dos cursos de graduação, em sua maioria, não aprofundam os estudos sobre as mais diversas infâncias e nem possuem mecanismos de vinculação entre a teoria estudada nas universidades e a prática das escolas infantis. Os professores quando estão na docência, por sua vez, participam de atividades formativas esporádicas, que não se constituem em um processo contínuo.

Peroza e Martins (p. 826-827, 2016) refletem sobre a profissionalidade docente e a educação da infância:

A profissionalidade docente, assim como a educação da infância, ainda se constitui enquanto um campo em construção, haja vista as lentas mudanças nos currículos do curso de Pedagogia, as propostas formativas distantes da realidade da prática e a desvalorização dos professores que atuam nesta etapa da educação. Espera-se que, a partir das práticas desenvolvidas com as crianças, no contexto das instituições, em diálogo com as descobertas e contribuições das diferentes áreas de conhecimento, possam se delinear os pressupostos formativos do professor da infância, bem como os elementos para sua profissionalização.

Ainda, há muito que se fazer para que tenhamos um atendimento de qualidade nas instituições infantis, que a formação continuada e a identidade do professor da infância sejam de fato valorizadas e que a prática pedagógica esteja em consonância com o desenvolvimento infantil.

A documentação pedagógica emerge no cenário brasileiro como um possível alento à tamanha complexidade da Educação Infantil. É uma prática com inspirações na pedagógica participativa de Reggio Emilia, ainda, recente no cenário brasileiro, que consiste basicamente na observação e registro do que fazem as crianças da Educação Infantil. Sua constituição é diversificada, porém não é plural, isto é, há muitas formas de realizá-la, mas apenas dois focos estruturantes: tornar visível e evidente as aprendizagens e a quem ela se destina (para quem será elaborada). É nesse viés que a documentação pedagógica pode constituir-se como um campo fértil da ação formadora de professores da infância, pois tornando visíveis as aprendizagens das crianças para os docentes, num movimento cíclico de escuta e olhar atentos, planejamento direcionado às demandas das crianças, propostas de experiências e brincadeiras significativas, reflexão das diversas interações e devolutivas, o professor 
pode analisar sua prática docente, por meio dos registros e confrontá-las com seus ideais, com seus pares e assim ressignificar a sua atuação e formação docente (Fochi, 2021).

\section{Iniciando Alguns Pensamentos}

Considerando a Educação Infantil como o lócus natural das experiências infantis com seus pares e adultos, assim como do adulto professor, o objetivo deste capítulo é discutir o conceito de experiência trazido por Larrosa (2002), no texto Notas sobre a experiência e o saber da experiência, no processo formativo do professor, na perspectiva da documentação pedagógica. Nesse sentido, para o autor citado a experiência é: "o que nos passa, o que nos acontece, o que nos toca. Não o que se passa não o que acontece, ou o que toca. A cada dia se passam muitas coisas, porém, ao mesmo tempo, quase nada nos acontece". (2002, p. 21)

Nessa perspectiva, Kishimoto destaca que a "formação do professor está completamente desconectada do lócus da prática profissional" imprimindo à formação de professores da Educação Infantil, seja ela inicial ou continuada no Brasil, uma lacuna entre a teoria e a prática pedagógica. Para tanto, utilizamos neste estudo, a perspectiva da documentação pedagógica, como possibilidade de formação docente, pois estudos recentes apontam-na "como possibilidade de interpretar a prática pedagógica para compreendê-la, reinterpretando-a para transformá-la (Fochi, 2015, p.45)" e como "prática investigativa que fomenta o desenvolvimento profissional (Gandini e Edwards, 2002, p.56) ”.

A documentação pedagógica possibilita ao professor aprender a olhar as experiências das crianças no cotidiano escolar, tomando-as como norte para seu fazer pedagógico, revelando o papel da criança no processo educativo e convidando o professor a se reposicionar frente ao contexto educativo e sua própria formação profissional (Fochi, 2015).

Nesse sentido, autores como Gandini e Edwards (2002) e Edwards, Gandini e Formam (1999) mencionam que a documentação é defendida como um processo que permite a reflexão por parte do educador e a expressão da experiência infantil. Sob esse ângulo, tal prática é entendida como um processo que envolve observação, registros e reflexão e poderá provocar alterações nas concepções e ações docentes.

Desta forma, utilizamos neste texto a metodologia do Estado da Arte que se caracteriza pela sua dimensão bibliográfica com o intuito de mapear e discutir temas como: experiência, formação docente, documentação pedagógica, na busca de responder quais aspectos vem sendo destacados e privilegiados, com o intuito de alcançar o objetivo proposto pelo estudo, permitindo o avanço do conhecimento científico (Minayo, 2011).

Pode-se caracterizar o estado da arte por sua "natureza inventariante e descritiva da produção acadêmica e científica sobre o tema que busca investigar, à luz de categorias e facetas que se caracterizam enquanto tais em cada trabalho e no conjunto deles, sob os quais o fenômeno passa a ser analisado" (Ferreira, 2002, p.258).

A documentação pedagógica é uma prática, ainda, recente nas discussões das pesquisas brasileiras, que vem crescendo vertiginosamente por levantar indícios de uma ação que possibilita um fazer democrático entre crianças, professores e famílias em torno das aprendizagens infantis. A intenção dessa discussão é levantar elementos que possibilitem destacar a documentação pedagógica como experiência formativa pela sua dimensão reflexiva no trabalho pedagógico do professor, levando-o a um aprimoramento contínuo na sua formação docente (Tardif, 2002).

\section{Aproximações entre Educação Infantil, a Identidade do Adulto Professor e a Documentação Pedagógica}

Espaço de educação formal, com especificidades próprias, por se tratar de bebês e crianças pequenas; o que a caracteriza com uma identidade única, que não assente a oferta de um atendimento meramente assistencialista, voltado apenas 
para os cuidados dos pequenos. Por outro lado, a busca por um modelo de instituição escolarizante, que prepara para a etapa seguinte, o Ensino Fundamental, não é o seu objetivo, já que vai de encontro ao postulado de tratar as crianças em suas singularidades (Abrão, 2012).

Sua finalidade é o desenvolvimento integral da criança, alicerçado em práticas que a concebam como protagonista dos seus processos de desenvolvimento e aprendizagem, por meio de vivências e experiências significativas. As Diretrizes Curriculares Nacionais para a Educação Infantil (Brasil, 2010) destaca a inerência entre o cuidar e o educar no atendimento às crianças pequenas, estabelece o currículo da Educação Infantil, especifica a necessidade da organização do fazer pedagógico com qualidade, vinculado à valorização do papel do professor.

Logo, o governo federal, por meio dos documentos de matriz oficial reconhece a criança como um sujeito de direito, com vontades, desejos e necessidades próprios; sujeito da sua aprendizagem. Aprendizagem que ocorre por meio de vivências significativas que atravessam e tocam as crianças.

Sujeito histórico e de direitos que, nas interações, relações e práticas cotidianas que vivencia, constrói sua identidade pessoal e coletiva, brinca, imagina, fantasia, deseja, aprende, observa, experimenta, narra, questiona e constrói sentidos sobre a natureza e a sociedade, produzindo cultura. (Brasil, 2010, p. 12).

Diante de este olhar singular para a primeira infância, o professor herda o desafio de planejar e propor atividades pedagógicas que "deem voz às crianças e acolham a forma delas significarem o mundo e a si mesmas" (Oliveira, 2017, p.01), alocando-as no centro do processo educativo, oportunizando que tenham experiências que contemple as múltiplas linguagens como forma de expressão e as interações e a brincadeira como eixos do trabalho pedagógico.

A Base Nacional Comum Curricular (Brasil, 2017) consolida as orientações das DCNEIs, ao reconhecer a Educação Infantil como etapa essencial e independente, assegurando-a como fundamental para a construção da identidade e da subjetividade das crianças. Estabelece seis direitos de aprendizagem e desenvolvimento: "Conviver, Brincar, Participar, Explorar, Expressar e Conhecer-se" (Brasil, 2018, p. 36), que se constituem como meios pelos quais as crianças aprendem e que os professores devem pautar-se ao planejar as propostas pedagógicas.

Propõe uma organização curricular alicerçada em cinco campos de experiências: " $O$ eu, o outro e o nós"; "Corpo, gestos e movimentos"; "Escuta, fala, pensamento e imaginação"; "Traços, sons, cores e imagens"; e "Espaços, tempos, quantidades, relações e transformações" (p. 38-41). Em cada campo de experiência é definido como os direitos de aprendizagem e desenvolvimento, devem ser garantidos, mediante, um conjunto de objetivos de aprendizagem e desenvolvimento para cada campo. Determina, ainda, três grupos etários: bebês (0-18 meses), crianças bem pequenas (19 meses a 3 anos e 11 meses) e crianças pequenas ( 4 anos a 5 anos e 11 meses).

Por meio, desses dispositivos legais - DCNEI e BNCC - há um grande avanço histórico ao compreender a criança "como sujeito histórico e de direitos, que, nas interações, relações e práticas cotidianas que vivencia, constrói sua identidade pessoal e coletiva, brinca, imagina, fantasia, deseja, aprende, observa, experimenta, narra, questiona e constrói sentidos sobre a natureza e a sociedade, produzindo cultura" (Brasil, 2009, p. 12).

Considerar a criança como sujeito é reconhecer sua natureza e singularidade, questões que ao longo do tempo foram negligenciadas. Compreender a criança como sujeito histórico é considerá-la potente e capaz de participar ativamente do seu próprio processo de aprendizagem e conhecimento, que por meio das relações que estabelece com seus pares, adultos, espaços, materiais e tempos manifestam suas ideias, desejos e capacidades de criar e decidir (Kramer, 2007).

Importante ponderar, para que, a concepção de criança amplamente discutida e propagada nos últimos anos, não seja naturalizada nos discursos de profissionais da educação, nas produções acadêmicas e documentos legais, sem o aprofundamento conceitual e consistente, com vistas à mudança da prática educativa dos professores (Fochi, 2015). 
Ao conceber essa ideia de criança protagonista, autônoma, ativa, que constrói seu próprio aprendizado e desenvolvimento, irrompe a necessidade de inaugurar outro modelo de professor da infância. "Nesse sentido a formação docente universitária e continuada salta à vista como uma possibilidade de efetivação da criança como sujeito de direitos" (Gonçalvez, 2016, p.12).

A Educação Infantil como espaço de convivência, de promoção da equidade, de acesso ao patrimônio que a humanidade já sistematizou precisa também inventar um modelo de professor, que ainda desconhecemos e que dê conta da sua complexidade (Fochi, 2021). Na Educação Infantil, a prática pedagógica é complexa e inacabada, por essa razão, demanda constante articulação entre teoria e prática, discurso e ação, por meio do processo de reflexão, tendo como direção os desafios verificados. Nesse cenário, a documentação pedagógica surge valorizando os saberes experienciais advindos da prática docente (Tardif, 2002).

A documentação pedagógica, por meio, das suas diversas possibilidades de registros realoca o professor como autor da sua prática e produtor de saberes, possibilitando que ao narrar a sua práxis, ele também argumente sobre ela. "Não são apenas memórias de algo que já aconteceu, são também processos que nos permitem compreender como fizemos o que fizemos" (Davoli, 2011, p. 28).

A documentação pedagógica possui um papel essencial na qualidade das práticas pedagógicas, uma vez que, possibilita aos professores planejarem contextos propícios às aprendizagens significativas das crianças, ao passo, que favorece o desenvolvimento profissional e a comunicação entre os adultos envolvidos no cotidiano infantil (Gandini, Edwards, 2002).

A documentação pedagógica se concretiza como a possibilidade de garantir efetivamente essa concepção de criança, como sujeito histórico e de direitos, ao possibilitar a transformação da prática pedagógica, por meio da investigação dos registros e memórias pelos professores e crianças, proporcionando, também no exercício reflexivo a formação docente.

A documentação pedagógica é chave para instituir a participação cotidiana das crianças, porque ajuda a ver, compreender e responder a cada criança e ao grupo, colocando-se no âmago da instituição dos direitos da criança no cotidiano educativo. [...] a análise e interpretação sistemática da documentação pedagógica é uma estratégia de monitorização essencial para garantir que os direitos da criança (direitos de aprendizagem e participação na vida da sala) sejam instituídos no cotidiano educativo (Oliveira-Formosinho \& Formosinho, 2017, p. 125).

\section{Documentação Pedagógica e a Construção de um Novo Modelo de Professor}

O conceito de documentação pedagógica surge na cena brasileira da Educação Infantil, a partir da difusão exitosa da experiência realizada, na cidade de Reggio Emilia, conduzida pelo jornalista e pedagogo Loris Malaguzzi, no final do século XX e fundamenta-se na ideia de "sistematização de percursos, elaboração da experiência e comunicação". (Marques, 2015, p. $3)$.

Gandini e Edwards (2002) concebem a documentação pedagógica enquanto prática cíclica. Primeiramente, existe a fase da formulação de perguntas e inquietações, em seguida, passa-se à observação do objeto a ser desvelado, depois o registro e produção de informações relevantes; após a organização dos dados coletados e registrados; chegando à análise e produção dos registros elaborados; o que desencadeará novos questionamentos e a elaboração de novos projetos e planejamentos.

Malaguzzi (1999) ancorado nos estudos de Edwards e Gandini (1999), criador do conceito de documentação pedagógica, compreende que uma teoria só possui validade se emerge de questões práticas vividas no ofício de ser professor. Logo se constitui na possibilidade de reflexão e mudança pedagógica:

Uma teoria é legítima se lida com problemas que emergem da prática da educação e que podem ser solucionados pelos educadores. A tarefa da teoria é ajudar para que os professores entendam melhor a natureza de seus problemas. Dessa forma, a prática torna-se um meio necessário para o sucesso da teoria (Malaguzzi apud Edwards, C.; Gandini, L.; Forman, G., 1999, p. 97) 
$\mathrm{Na}$ busca dessa reflexividade do professor que acolhe o universo das crianças e da escola como espaço privilegiado para a construção do conhecimento, a Educação Infantil depara-se com a necessidade de outra pedagogia. Apenas, uma pedagogia participativa (Formosinho, J.; Oliveira -Formosinho, J., 2008) possibilita dar conta dessa ideia de docência, criança e de Educação Infantil. Por esse motivo que a documentação pedagógica pode ser uma importante resposta contra a traição do potencial das crianças e dos adultos. A documentação pedagógica não cabe em uma pedagogia qualquer, ao contrário é uma estratégia que responde ao complexo processo formativo do professor, pois reivindica outra imagem de criança e de adulto e situa-se em uma perspectiva de criança aberta à construção de sentidos (Fochi, 2015).

\section{Interfaces entre Experiência, Sujeito da Experiência, Saber da Experiência e a Documentação Pedagógica}

Larrosa (2002) convida a pensar a Educação, por meio, do par experiência/sentido. Pensar, então, não seria um fenômeno puramente cognitivo e sim a impressão de sentido que o ser humano dá aos acontecimentos e a sua singularidade. Esse sentido só é possível, a partir, das palavras. Palavras que dão potência ou inércia.

As palavras com que nomeamos o que somos, o que fazemos, o que pensamos, o que percebemos ou o que sentimos são mais do que simplesmente palavras. E, por isso, as lutas pelas palavras, pelo significado e pelo controle das palavras, pela imposição de certas palavras e pelo silenciamento ou desativação de outras palavras são lutas em que se joga algo mais do que simplesmente palavras, algo mais que somente palavras (Larrosa, 2002, p.21).

A palavra experiência seria o que nos afeta, o que nos atravessa o que nos transforma, em meio, aos diversos acontecimentos cotidianos. Sempre em uma perspectiva de perigo e travessia pela indeterminação própria da vida. Contudo, a pobreza de experiência é cada vez mais comum no mundo contemporâneo. Em seus estudos, Larrosa (2002), aponta quatro aspectos determinantes: o excesso de informação, a exorbitância de opinião, a falta de tempo e o excesso de trabalho.

A informação em demasia nos leva ao empobrecimento de experiências. Cada vez mais temos acesso a uma gama diversa de informações, em um tempo cada vez mais veloz, principalmente, por meio de telas eletrônicas. A todo instante estamos fisicamente em um momento presente, mas em vários lugares ao mesmo tempo, em uma busca desenfreada por informação. A satisfação não nos atinge, a agitação por novidades é permanente, logo continuamos na saga de saber mais e nos constituímos como seres ultrainformados (Sarmento, 2011).

Dessa forma, é importante pontuar que informar- se é diferente de experimentar a vida, logo o saber advindo das coisas é diferente do saber da experiência. No dia-a-dia vivemos diversos acontecimentos, que em alguma medida nos informam sobre uma série de conhecimentos, porém nem sempre algo nos arrebata. O saber da experiência só é possível se algo nos chega, nos mobiliza, nos fascina. O conhecimento e a aprendizagem não se dão, apenas, pelo ato de informar-se. Ao contrário, aprender está intrinsicamente relacionado ao envolvimento com um acontecimento, com uma experiência.

Depois de assistir a uma aula ou a uma conferência, depois de ter lido um livro ou uma informação, depois de ter feito uma viagem ou de ter visitado uma escola, podemos dizer que sabemos coisas que antes não sabíamos, que temos mais informação sobre alguma coisa; mas, ao mesmo tempo, podemos dizer também que nada nos aconteceu, que nada nos tocou, que com tudo o que aprendemos nada nos sucedeu ou nos aconteceu. (Larrosa, 2002, p.22).

Se o sujeito da informação é aquele que demanda informação incessantemente podemos apontar, aqui, para como os professores atualmente pesquisam em sites de buscas respostas para o seu fazer pedagógico. Muitas das vezes, depara-se com um repertório de atividades prontas, mecânicas e desarticuladas da dinâmica singular do grupo de crianças com o qual trabalha. Diante, dessa enxurrada de informações, com um cardápio vasto de atividades elenca aquelas que julgam mais interessantes, 
sem levar em conta os verdadeiros interesses, necessidades e curiosidades das crianças, empobrecendo, assim os agentes disparadores da aprendizagem infantil.

Do ponto de vista da documentação pedagógica como instrumento potencializador da formação docente é relevante destacar que esta não se configura como um compilado de informações e registros das experiências infantis. $\mathrm{O}$ ato de documentar requer seleção, foco, um fio condutor (Marques; Almeida, 2002). Assim, nem todas as informações que um grupo de crianças pode oferecer ao professor, são de fato significativas para a documentação. Então, não é a quantidade de informações diversas que dará forma à documentação e sim o olhar criterioso e atento do professor, o que o embevecerá, e o inspirará, e determinará a coleta de dados significativos à compreensão e a análise crítica das experiências infantis.

Bombardeados por informações, logo, o ser humano inclina-se a opinar sobre tudo e, se não, opina não se sente parte da dinâmica social. A sociedade apresenta-se como um imperativo à overdose de informação e opinião. Nesse sentido, há um casamento perfeito, para que, nada toque o indivíduo. Para que a experiência, de fato, não tenha lugar de ser (Sarmento, 2011),

No que tange à Educação, a dinâmica, entre o par informação/opinião nos assola desde a Educação Infantil até o Ensino Superior. Aprender seria como informar-se sobre algo, estaria no campo do objetivo. Significar esse algo, seria a opinião sobre a informação adquirida, manifestando-se a favor ou contrário ao que acontece, ao que se passa. A ideia de aprendizagem, então, resume-se a identificar o que o sujeito sabe, que informação possui sobre determinada coisa e sua opinião sobre a mesma. "esse o dispositivo periodístico do saber e da aprendizagem, o dispositivo que torna impossível a experiência" (Larrosa, 2002, p.23).

Munido de um aporte de informações esse professor opina, solitário, sobre o que entende ser mais acertado para o trabalho pedagógico, embora, descontextualizado da realidade das crianças, cancelando a possibilidade de experiência que a documentação pedagógica suscita de troca entre seus pares professores, quando os convida, no coletivo, à interpretação das documentações como oportunidade para refletir, ressignificar as práticas e verificar avanços e desafios do cotiando (Fochi, 2015).

O tecido da documentação é organizado, alinhavado para ser compartilhado, inicialmente, com os colegas professores da creche. A tessitura está imbuída de subjetividade daquele que tece. Após esta se oferece à subjetividade interpretativa dos outros, de modo que o tecido possa ser conhecido, reconhecido, criado, recriado. Uma espécie de interpretação em companhia, uma vez que novas apropriações podem ser feitas no encontro com outras professoras. (Simiano, 2016, p. 05)

A falta de tempo é outro aspecto que contribui para a pobreza de experiências. Atualmente, vivemos uma sociedade de estímulos constantes e acelerados. Somos levados cada vez mais a consumir notícias, novidades, informações a respeito de tudo, o tempo todo e ao mesmo tempo. A vida acontece em uma dinâmica pontual, instantânea e fragmentada. A velocidade das vivências impossibilita a conexão significativa entre os acontecimentos como também a memória, já que, um estímulo é substituído por outro lepidamente (Sarmento, 2011).

Ao sujeito do estímulo, da vivência pontual, tudo o atravessa, tudo o excita, tudo o agita, tudo o choca, mas nada lhe acontece. Por isso, a velocidade e o que ela provoca, a falta de silêncio e de memória, são também inimigas mortais da experiência. (Larrosa, 2002, p.23).

O campo educacional encaixa-se nessa mesma lógica destrutiva e incapacitante da possibilidade da experiência, ao inserir-se em um tempo sobremodo acelerado (Kramer, 2007). Ao longo da vida, passa-se um período cada vez maior nas instituições de ensino, isocronamente, temos menos tempo para experienciar a vida escolar/acadêmica. Já que, estamos sempre à procura do novo, do ineditismo constante, do que há por vir. A organização curricular está sucessivamente organizada em uma quantidade maior de estruturas de conhecimentos, contudo em uma durabilidade de tempo cada vez menor. Não há tempo para demorar-se sobre as vivências educativas. 
Esse sujeito da formação permanente e acelerada, da constante atualização, da reciclagem sem fim, é um sujeito que usa o tempo como um valor ou como uma mercadoria, um sujeito que não pode perder tempo, que tem sempre de aproveitar o tempo, que não pode protelar qualquer coisa, que tem de seguir o passo veloz do que se passa, que não pode ficar para trás, por isso mesmo, por essa obsessão por seguir o curso acelerado do tempo, este sujeito já não tem tempo (Larrosa, 2002, p.23).

A documentação pedagógica vem na contramão dessa lógica delirante. Nos convoca a um gesto de interrupção da celeridade dos processos, a demorarmo-nos sobre as experiências infantis, a nos disponibilizarmos a uma escuta sensível e a um olhar atento sobre as crianças (Pinazza \& Fochi, 2018). Documentar possibilita a preservação das memórias do vivido num tempo e num espaço único, evidenciando as experiências infantis, permitindo que professores e crianças revisitem, reconstruam e ressignifiquem o vivido (Larrosa, 2002).

Documenta-se para conservar a memória dos acontecimentos, das experiências, imprimindo uma identidade ímpar aos fatos, não como um processo puramente burocrático, mas de autoria e singularidade do vivido pelas crianças e adultos. "A documentação visa à tessitura de uma narração única e coerente de um projeto colocado em ação com consistência e profundidade, permitindo a construção de sentido" (Marques; Almeida, 2012, p.450).

Por fim, a experiência é cada vez mais incomum pelo excesso de trabalho. É necessária a distinção entre trabalho e experiência. Há um lugar comum no ideário social de que nas instituições de ensino aprende-se a teoria e no trabalho obtém-se a experiência, por meio, da prática. Porém trabalho e experiência são distintos. $\mathrm{O}$ trabalho é uma relação com a vida que impossibilita a experiência. $\mathrm{O}$ trabalho está no campo do mercantil, da moeda de troca, da barganha feroz do capitalismo. $\mathrm{O}$ que não dialoga com a concepção de experiência aqui explanada.

O sujeito contemporâneo possui a pretensão de mudar a sua realidade e essa mudança dar-se, através do trabalho. Propõe-se a fazer muitas coisas e crê que nada pode ser um obstáculo ao seu desejo. Há um misto de otimismo, progressismo e agressividade para alcançar o que deseja (Larrosa, 2017).

Nós somos sujeitos ultra-informados, transbordantes de opiniões e superestimulados, mas também sujeitos cheios de vontade e hiperativos. E por isso, porque sempre estamos querendo o que não é, porque estamos sempre em atividade, porque estamos sempre mobilizados, não podemos parar. E, por não podermos parar, nada nos acontece. (Larrosa, 2002, p.24).

Em Educação Infantil, podemos observar, muitas vezes, essa lógica incapacitante do trabalho, que anula a possibilidade da experiência docente. Vivemos ainda uma concepção educativa onde a interferência automática, sistemática, lépida e invasiva do professor é o fio condutor do trabalho pedagógico (Larrosa, 2012). Daquele professor que precisa cumprir um plano rígido, engessado, onde uma atividade se sobrepõe a outra em uma dinâmica afobada. Porque acredita que quanto mais informação, quanto mais estímulo, quanto mais otimizar o tempo, mais possibilidade a criança terá de "ser alguém" (Sarmento, 2011). Porque a criança que é hoje, não é o suficiente para este adulto. Ele trabalha com a ideia da criança que virá a ser. Daquela criança que ele precisa preparar para a próxima etapa. Daquela criança que não é um sujeito de direito, que não participa do seu próprio processo educativo. Por isso, o professor corre (Abrão, 2014).

Documentar, então, seria uma forma de resistência, pois, só é possível realizarmos uma documentação pedagógica, se primeiramente oportunizarmos. As crianças construírem seus percursos de aprendizagens. Para tanto, é preciso que o professor oferte tempo, espaço, materiais e interações significativas. O que demanda uma pausa nos processos educativos céleres.

Larrosa (2002) ressalta, também, que o trabalho é uma forma de conformar o mundo. Enquanto, professores quantas vezes não desejamos conformar o ser criança a uma ideia de infância a ser moldada? Na direção oposta, a concepção de documentação pedagógica concebe as crianças como seres ativos, repletos de potência, protagonistas das suas aprendizagens, onde o professor atua numa postura de intervenção delicada, atenta e observadora das experiências infantis, com o objetivo de colher elementos relevantes para a documentação. 
A experiência "requer um gesto de interrupção. Parar para pensar, olhar, escutar mais devagar, demorar nos detalhes, suspender julgamentos, cultivar a atenção, aprender a lentidão, cultivar o encontro, ter paciência” (Horn; Silva, 2011.p.137). Nesse sentindo, a experiência e o ato de documentar aproximam-se, já que, para documentar é necessário distanciar-se, refletir e desacelerar do ritmo frenético do fazer educativo, na tentativa de captar e dar sentido às experiências infantis, buscando reunir elementos soltos do cotidiano infantil, que por vezes parecem fragmentados e desconexos.

Se a experiência é aquilo que nos toca, nos afeta, nos atravessa e a pobreza de experiência está marcada pelo bombardeio excessivo de informação, pela exacerbada necessidade de opinião, pelo excesso de trabalho, pela escassez de tempo. Quem é o sujeito da experiência?

O sujeito da experiência é aquele que se permite ser afetado. Inaugura uma abertura para que algo o encontre. Estreia uma disponibilidade para que alguma coisa o atravesse. Funda uma receptividade à transformação de si. Concebe uma vulnerabilidade consentida, para que a potência se revele. Logo as pesquisas de Larrosa (2002, p.25) afirmam que: "é incapaz de experiência aquele a quem nada lhe passa, a quem nada lhe acontece, a quem nada lhe sucede, a quem nada o toca, nada lhe chega, nada o afeta, a quem nada o ameaça, a quem nada ocorre".

O professor ao se propor documentar as infâncias, antes de tudo, precisa se permitir ser afetado pelas experiências infantis. As brincadeiras, as interações, as experiências, as pesquisas infantis convidam. Contudo, o professor precisa inaugurar, em si, a abertura para contemplar e se permitir ser atravessado pelas infâncias. Precisa ser inaugurada uma disponibilidade a outro modo de pensar a ação educativa. Por meio, dessa abertura o professor conquista a possibilidade de experimentar outros olhares e sentidos na cena educativa, despertando -se à transformação (Marques; Almeida, 2012).

$\mathrm{O}$ sujeito da experiência pode ser transformado em um espaço de tempo efêmero ou na passagem do tempo, o que determina a característica formadora e transformadora da experiência. O sujeito da experiência refere-se ainda à ideia de paixão, de se permitir ser afetado por algo exterior mesmo que tenha a liberdade para não o fazer, "um território de passagem, algo como uma superfície de sensibilidades na qual aquilo que passa afeta de algum modo, produz alguns afetos, inscreve algumas marcas, deixa alguns vestígios, alguns efeitos" (Larrosa, 2004, p.160).

Desta forma, o professor que permite que as experiências infantis o interpelem, pode ser por elas alcançado no momento, no qual elas sucedem ou no decorrer das vivências infantis. A documentação mais uma vez relaciona-se a essa ideia de experiência, ao proporcionar ao adulto revisitar seus registros e por ele ser transformado, no exercício da reflexão, buscando compreender e problematizar a natureza dessas memórias.

O saber científico e o saber da informação são perenes já que são saberes instituídos por outrem e que nos remete à dinâmica de consumir esse conhecimento para atender uma demanda particular, utilizando-o para algum fim. O saber da experiência é diferente. Está vinculado à ideia de aprendizagem do e no que nos acontece, ou seja, na forma como respondemos aos acontecimentos e como vamos imprimindo significado ao que nos acontece. Assim, é um saber finito, subjetivo, particular, intransferível, pessoal.

A documentação pedagógica em sua dimensão formativa remete-se ao saber da experiência ao possibilitar que o professor transforme-se, por meio, da sua própria produção e prática educativa, uma vez que, representa um instrumento a ser utilizado nos momentos de planejamento da ação pedagógica e de formação em serviço, que acarretará na "percepção de aspectos significativos da atividade didática, a tomada de consciência de elementos não compreendidos em suas implicações, o confronto, o aprofundamento de dimensões da profissionalidade docentes antes ignorados (Marques; Almeida, 2012, p.446).

Por fim, o professor ao iniciar um processo de documentação deve considerar que está lançando-se a um projeto que precisa ter um eixo norteador, um fio condutor como critério para a seleção do que registrar, para que fazê-lo, para quem?, como documentar?, Quem irá fazê-lo?, qual a realidade a ser descrita e os suportes para registrar. Dessa forma, a documentação pedagógica, na perspectiva da formação docente pode contribuir para que a experiência aconteça, ao convidar o 
professor a rememorar as vivências infantis, refletir sobre elas e sobre sua proposta de trabalho pedagógico, buscando novas formas de trabalhar e de oferecer interações e brincadeiras significativas às crianças. Além disso, caracteriza-se como um campo fértil para a projetação de novas experiências de crianças e adultos dentro do contexto educativo (Pinazza, Fochi, 2018).

A documentação pedagógica se configura como uma ferramenta poderosa e produtiva de formação profissional docente, tendo em vista o potencial que imprimi, ao convidar o professor a pensar de outro modo sobre o que se sabe e o que se faz no cotidiano da Educação Infantil (Larrosa, 2016). Nessa perspectiva, reitera-se sua dimensão formativa, já que, estabelece uma forma de se relacionar inovadora, não só com as crianças, mas com os demais adultos com os quais o professor lida. Ao constituir-se como uma produção pedagógica, também se revela importante instrumento de trabalho, ao estimular o crescimento profissional, a qualificação do serviço a construção de condições de trabalho adequadas (Fochi, 2015).

\section{Referências}

Abrão, K. (2011). O espaço o movimento e o brincar no período de transição da Educação Infantil e o primeiro ano. 2011. Dissertação (Mestrado em Educação Física), Universidade Federal de Pelotas, Pelotas.

Abrão R. K. (2012). A Política de Organização das Infâncias e o currículo da Educação Infantil e do primeiro ano. Zero-a-seis (Florianópolis), $25,51-74$.

Abrão R. K. (2014). O Espaço Físico da Sala de Aula da Educação Infantil e do primeiro ano e a corporeidade da criança. The FIEP Bulletin, 84, 1-7.

Barbosa, M. C. S., Fernandes, S. B. (2018). Uma ferramenta para educar-se e educar de outro modo. <http://loja.grupoa.com.br/revista-patio/artigo/6243/umaferramenta-para-educar-se-e-educar-de-outro-modo.aspx>.

Brasil (2018). Base Nacional Comum Curricular: Educação é a base. http://basenacionalcomum.mec.gov.br/wp-content/uploads/2018/02/bncc-20dez-site.pdf.

Brasil, (2009). MEC, CNE, CEB. Diretrizes Curriculares Nacionais para a Educação Infantil. Resolução nº 5 , de 17 de dezembro de 2009.

Brasil, (2017). INEP, MEC. Censo Escolar 2016: notas estatísticas. 2017.

Brasil. (2010). Ministério da Saúde. Portaria n 4.279, de 30 de dezembro de 2010. Estabelece diretrizes para a organização da Rede de Atenção à Saúde no âmbito do Sistema Único de Saúde (SUS). Diário Oficial da União 31 dez 2010, Seção 1.

Brasil.(1996). Lei de Diretrizes e Bases da Educação Nacional. Lei número 9394, 20 de dezembro de 1996.

Bresci, L. et al. (2007). La documentazione: un modo di fare educazione. In: Scuola dell'infanzia, settembre.

Davoli, M (2011). Documentar procesos, recoger siñales. In: RED TERRITORIAL DE EDUCACIÓN INFANTIL DE CATALUÑA. Documentar la vida de niños y niñas en la escuela. Octaedro, 2011.

Edwards, C., et al. (1999). As cem linguagens da criança: a abordagem de Reggio Emília na educação da primeira infância. Artes Médicas Sul, 1999.

Fochi, P. S. (2021). Criança, currículo e campos de experiência: notas reflexivas/Child, curriculum and fields of experience: reflective notes. CONJECTURA: filosofia e educação, 25, 52-72.

Fochi, P.S. (2015). Ludicidade, continuidade e significatividade nos campos de experiência. In: Finco, D., Barbosa, M.C.S., Faria, A.L.G. de (orgs.). Campos de experiência na escola da infância: contribuições italianas para inventar um currículo de educação infantil brasileiro. Leitura Crítica.

Formosinho, J. (2017). A educação em creche: os desafios das pedagogias com nome. In: Oliveira-Formosinho, J. (Org.). Modelos pedagógicos para a educação em creche. Porto Editora.

Formosinho, J., \& Oliveira-formosinho, J. (2008). Pedagogy-in-Participation: Childhood Association's approach. Aga Khan Foundation.

Freire, M (1996). O registro e a reflexão do educador. In: Freire, M (coord). Observação, registro, reflexão - Instrumentos metodológicos I. São Paulo: Espaço Pedagógico.

Gandini, L, \& Edwards, C. (2002). Bambini: a abordagem italiana à educação infantil. Artmed.

Gatti, B. A., \& Barretto, E. S. S. (Coord.) (2009). Professores do Brasil: impasses e desafios. UNESCO.

Gonçalvez. G. (2016). A criança como sujeito de direitos: limites e possibilidades. Reunião Científica regional da ANPED. 2016.

Horn, C. I., \& da Silva, J. S. (2011) Experiências e documentação: é possível articular estes conceitos??. Reflexão e Ação, 19, 136-145

Kishimoto, T. M (2004). O sentido da profissionalidade para o educador da infância. In: Barbosa, R. L. L. (Org). Trajetórias e perspectivas da formação de educadores. Editora UNESP..

Kramer, S. (2007). A infância e sua singularidade. In: BEAUCHAMP, Janete, PAGEL, Sandra Denise, Nascimento, Aricélia Ribeiro do (org.). Ensino fundamental de nove anos orientações para a inclusão da criança de seis anos de idade. (2a ed.), Leograf. 
Research, Society and Development, v. 10, n. 9, e15010917782, 2021

(CC BY 4.0) | ISSN 2525-3409 | DOI: http://dx.doi.org/10.33448/rsd-v10i9.17782

Larrosa, J. (2002). Notas sobre a experiência e o saber da experiência. Revista Brasileira de Educação, nº.19.

Malaguzzi L. (1999). Histórias, ideias e filosofia básica. In: Edwards, C., Gandinui, L., Forman, G. As cem linguagens da criança: a abordagem de Reggio Emília na educação da primeira infância. Porto Alegre: Artes Médicas Sul.

Marques, A. C. T. L. (2015). A Documentação Pedagógica no Cotidiano da Educação Infantil: estudo de caso em pré-escolas públicas. $37^{a}$ Reunião Nacional da ANPEd-04 a 08 de outubro de 2015. Educação em Revista, 213-225.

Marques, A. C. T. L, \& De Almeida, M. I.(2012). A documentação pedagógica na abordagem italiana: apontamentos a partir de pesquisa bibliográfica. Revista Diálogo Educacional, 12, 441-458

Minayo, M. C. de S. (2011). Pesquisa Social. Teoria, método e criatividade, ed. Petrópolis: Vozes.

Oliveira, Z. de M. R. de (2017). O currículo na educação infantil: o que propõem as novas diretrizes nacionais.

Oliveira-Formosinho, J. \& Formosinho, J (2017). Pedagogia-em-Participação: a documentação pedagógica no âmago da instituição dos direitos da criança no cotidiano. 30 .

Oliveira-Formosinho, J., \& Formosinho, J. (2011). A Perspectiva Pedagógica da Associação Criança: A Pedagogia-em-Participação, IN: Oliveira-Formosinho, J., Formosinho, J. (Orgs). O Trabalho de Projeto na Pedagogia-em-Participação. Porto Editora, 2011. p. 11-45.

Pinazza, M. A., \& Fochi, P. S.(2018). Documentação Pedagógica: observar, registrar e (re)criar significados. Revista Linhas. 19, 184-199.

Sarmento, M. J. (2011). As culturas da infância nas encruzilhadas da $2^{a}$ modernidade.

Sarmento, M. J. A reinvenção do ofício de criança e de aluno. In: Atos de Pesquisa em Educação. 6, 581 - 602.

Sarmento, M. J. Gerações e alteridade: interrogações a partir da Sociologia da Infância. In: Educação Social, 26, 361 - 378. https://doi.org/10.1590/S010173302005000200003

Simiano, L. P. (2016). O Processo de Documentação Pedagógica e a Tessitura de Narrativas na Creche: Entre Fios e Desafios. Reunião Científica Regional da ANPED-24 a 27 de julho de 2016.

Tardif, M. S. (2002). Os professores diante do saber: esboço de uma problemática do saber docente. In: TARDIF, M. Saberes docentes e formação profissional. Vozes. 31-55.

Zabalza, M. Á. (1994). Diários de Aula - Contributo para o estudo dos dilemas práticos dos professores. Porto Editora. 